\title{
UPS Study of Poly(phenylenevinylene)s Substituted with Hexyloxy, Phenoxy, and Nitroxy Residues
}

\author{
Takashi Kaneko, Eisuke Ito, ${ }^{*}$ Kazuhiko SeKI, ${ }^{*}{ }^{\dagger}$ \\ Eishun TsuCHIDA, ${ }^{\dagger}$ and Hiroyuki NisHIDE ${ }^{\dagger}$ \\ Department of Polymer Chemistry, Waseda University, Tokyo 169, Japan \\ * Department of Chemistry, Nagoya University, Nagoya 464, Japan
}

(Received October 2, 1995)

\begin{abstract}
KEY WORDS Substituted Poly(phenylenevinylene) / Ultraviolet Photoelectron Spectroscopy (UPS) /
\end{abstract} Ionization Potential / $\pi$-Conjugation / Electronic Structure / Polyradical /

Poly(phenylenevinylene) (PPV) derivatives have recently attracted attention as some of the most interesting polymers with electrical conduction and unique optical properties. ${ }^{1-3}$ Especially, substituted PPVs are high potential candidates for the functional polymers due to their solvent-solubility and the tunability of electronic properties by the substituents. ${ }^{4-6}$ The authors at Waseda University recently reported that poly $(1,4-$ or 1,2-phenylenevinylene) (1,4- or 1,2-PPV) bearing a stable radical such as $\mathbf{1 e}, \mathbf{2 e}$, and $\mathbf{2 f}$ realized ferromagnetic spin alignment through the $\pi$-conjugated PPV backbone. ${ }^{7,8}$ The electronic structure of the PPV backbone is deeply correlated with the magnetic interaction. The electronic structure of unsubstituted 1,4-PPV was investigated using UV/vis spectroscopy, ${ }^{9}$ ultraviolet photoelectron spectroscopy (UPS), ${ }^{10,11}$ and MO calculations, ${ }^{12-15}$ which have not been applied well to substituted 1,4-PPVs and not yet to 1,2-PPVs. In this paper, we studied the UPS of the PPV derivatives for fully discussing the influence of the substituent group with the aid of UV/vis absorption.

\section{EXPERIMENTAL}

Poly(1,2-phenylenevinylene) (2a), poly[(2-hexyloxy1,4-phenylene)vinylene $]$ (1b), poly[(4-hexyloxy-1,2phenylene)vinylene] (2b), poly[[2-(3,5-di-tert-butyl-4hydroxyphenyl)-1,4-phenylene]vinylene] (1c), poly[[4(3,5-di-tert-butyl-4-hydroxyphenyl)-1,2-phenylene]vinylene $]$ (2c), poly[[2-[N-tert-butyl- $N$-(triethylsiloxy)amino]-1,4-phenylene $]$ vinylene $]$ (1d), and poly[[4-[Ntert-butyl- $N$-(tert-butyldimethylsiloxy)amino]-1,2-phenylene]vinylene] (2d) were prepared via polymerization of the corresponding bromostyrene derivatives using Heck reaction, and their head-to-tail and trans-vinylene connected structure were confirmed. ${ }^{5,7,8}$ The molecular weight $\left(M_{w}\right)$ of these polymers was determined by GPC using a polystyrene standard to be $1.1 \times 10^{3}(\mathbf{2 a})$, $8.6 \times 10^{3}(\mathbf{1 b}), 2.6 \times 10^{3}(\mathbf{2 b}), 3.8 \times 10^{3}(\mathbf{1 c}), 5.1 \times 10^{3}$ (2c), $2.8 \times 10^{3}(\mathbf{1 d})$, and $2.7 \times 10^{3}(\mathbf{2 d})$, respectively. As dimer and trimer model compounds for 1c, 4-methyl3,2'-bis(3,5-di-tert-butyl-4-hydroxyphenyl)stilbene (3), and 1-[4-methyl-3-(3,5-di-tert-butyl-4-hydroxyphenyl)styryl]-4-[2-(3,5-di-tert-butyl-4-hydroxyphenyl)styryl]benzene (4) were also synthesized. ${ }^{8}$ The polyradicals $1 e$, $\mathbf{1 f}, \mathbf{2 e}$, and $\mathbf{2 f}$ were prepared via oxidation of the cor-

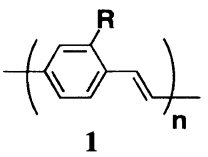

a: $\mathbf{R}=\mathbf{H}$

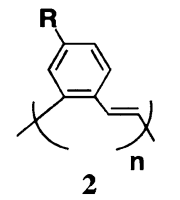<smiles>CC(C)(C)c1cc(C#P)cc(C(C)(C)C)c1O</smiles>

e: $\mathbf{R}$<smiles>COc1cc(C=P)cc(C(C)(C)C)c1OC</smiles>

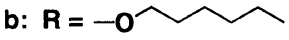<smiles>CCON(C=[Ge])C(C)(C)C</smiles>

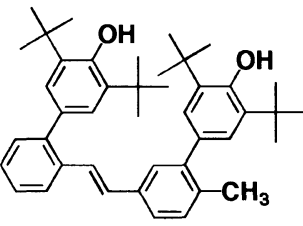

3

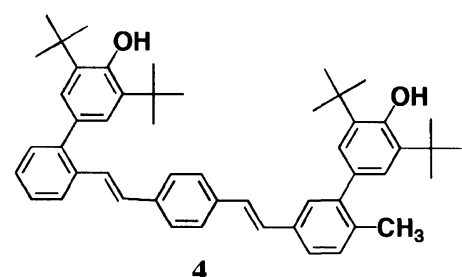

Chart 1. 
responding polymers $\mathbf{1 c}, \mathbf{1 d}, \mathbf{2 c}$, and $\mathbf{2 d}$ using freshly prepared $\mathrm{PbO}_{2}$ in THF. The spin concentration of polyradicals was determined as $31,14,59$, and $83 \mathrm{~mol} \%$ for $\mathbf{1 e}, \mathbf{1 f}, \mathbf{2 e}$, and $\mathbf{2 f}$, respectively, by careful integration of the ESR signals by comparison with those of the TEMPO (2,2,6,6-tetramethyl-1-piperidinyloxy) solution as a standard. These polymers were spin-coated on a polished copper substrate.

The UPS spectrometer consists of a mercury lamp $(6.72 \mathrm{eV})$ operated by microwave discharge and a retarding-field type electron energy analyzer with a resolution of $c a$. $0.2 \mathrm{eV}$. UPS spectra were measured in a manner analogous to that described in ref 16 .

\section{RESULTS AND DISCUSSION}

As an example the UPS spectra are shown in Figure $\mathbf{1}$ for $\mathbf{1 b}$ and $\mathbf{2 b}$. The peaks of these polymers are unimodal and fine structure are not observed. The values of ionization threshold $\left(I^{\text {th }}\right)$ for these polymers were determined from the UPS spectra, and are summarized in Table I.

The values of $I^{\text {th }}$ for 2 are larger than those of the corresponding $\mathbf{1}$ including the substituted PPVs $\mathbf{1 b} \mathbf{d}$ and $\mathbf{2 b}-\mathbf{d}$. This agrees with the trend in the $U \mathrm{~V} / \mathrm{vis}$ absorption; the absorption maxima of 1 (at $390-400 \mathrm{~nm}$ ) are observed at the longer wavelength as compared to those of 2 (at $330-380 \mathrm{~nm}$ ). These results indicate that the conjugation around the PPV backbone in 1,4-PPV is developed as compared with that of the corresponding 1,2-PPV.

As for the influence of the substituent group, the observed $I^{\text {th }}$ s can be summarized as $\mathbf{b}<\mathbf{c}<\mathbf{d}$ for both of

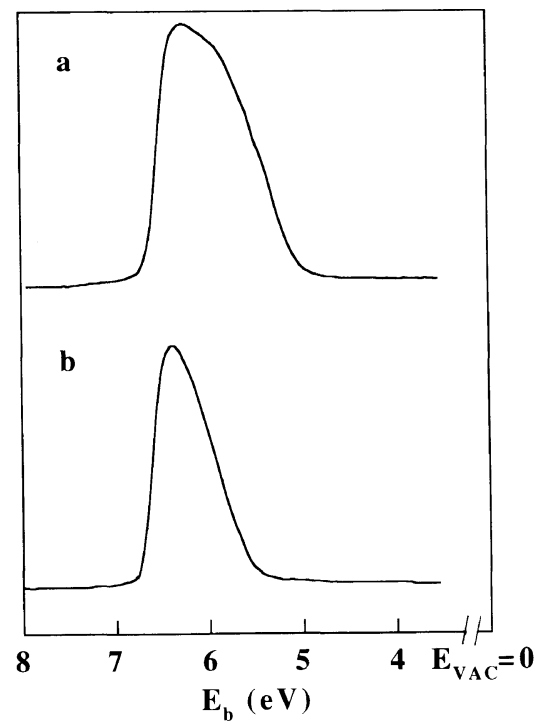

Figure 1. UPS spectra of $\mathbf{1 b}$ and $\mathbf{2} \mathbf{b}$.

Table I. Ionization threshold energies $\left(I^{\text {th }}\right)$ of $\mathbf{1}$ and $\mathbf{2}$

\begin{tabular}{|c|c|c|c|c|c|c|}
\hline \multirow{2}{*}{ Polymer } & \multicolumn{6}{|c|}{$I^{\mathrm{th}} / \mathrm{eV}$} \\
\hline & $\mathbf{a}$ & b & c & d & e & f \\
\hline 1 & $5.2^{\mathrm{a}}$ & $5.0_{8}$ & $5.5_{7}$ & $5.6_{7}$ & $5.7_{0}$ & $5.7_{8}$ \\
\hline 2 & $5.9_{0}$ & $5.5_{4}$ & $5.6_{5}$ & $5.8_{7}$ & $5.8_{1}$ & $5.5_{4}^{\circ}$ \\
\hline
\end{tabular}

${ }^{a}$ Cited from ref 10.

Polym. J., Vol. 28, No. 2, 1996 $\mathbf{1}$ and 2. The change in the $I^{\text {th }}$ for $\mathbf{1}$ may come from factors such as steric hindrance between the bulky substituent group and PPV backbone, and/or the electronic interaction between the main chain and side chain substituent. The former increases $I^{\text {th }}$, while the $I^{\text {th }}$ of $\mathbf{1 b}$, which has less bulky and electron donative substituent, is much smaller than that of the unsubstituted PPV 1a. ${ }^{10}$ Fahlman et al. noted that the substituent groups of 1,4-PPV could affect $\pi$-band structure by electronic interactions between side groups and the phenyl ring, by inducing increased torsion due to steric hindrance between the side groups and the vinylene hydrogens, or by locking the geometry into a coplanar configuration due to hydrogen-type bonds between the side groups and vinylene hydrogens. ${ }^{17}$ On the other hand, the decrease of $I^{\text {th }}$ for $\mathbf{2}$ by substitution should be ascribed to the increase in the degree of mixing with the PPV backbone by the reduction of the energy difference between the main chain and side chain substituent, because the steric hindrance between the bulky side groups and vinylene hydrogens in $\mathbf{2}$ is negligible for the substitution on the 4- or 5-position of the 1,2-PPV chain. The large $I^{\text {th }}$ of $2 \mathrm{~d}$ suggests that the mixing may be reduced by the large twisting angle between the NO bond and phenyl plane due to the simultaneous incorporation of two bulky substituents, the tert-butyl group and the tert-butyldimethylsiloxy group.

The relationship between the $I^{\text {th }}$ of these polymers and transition energy (4) from UV/vis absorption spectra are shown in Figure 2. The $\Delta$ is estimated from the absorption maxima for $\mathbf{1}$, and from the absorption

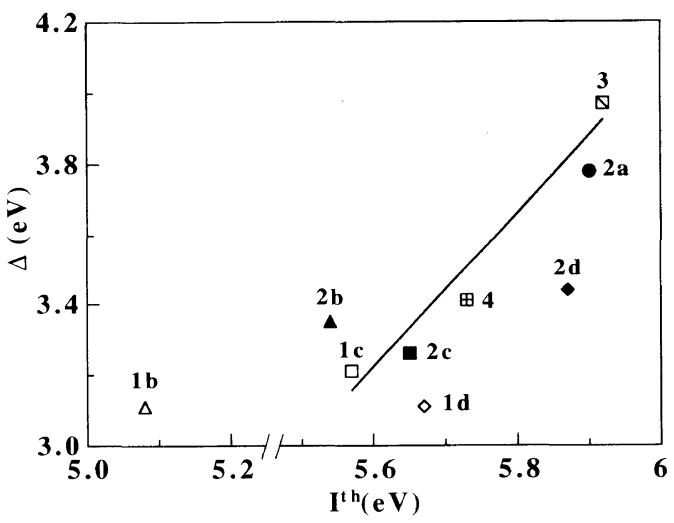

Figure 2. Ionization threshold energy $\left(I^{\text {th }}\right) v s$. transition energy $(\Delta)$ from UV/vis absorption spectra for $\mathbf{2 a}(\mathbf{O}), \mathbf{1 b}(\triangle), \mathbf{2 b}(\mathbf{\Delta}), \mathbf{1 c}(\square)$, 2c $(\square)$, 1d $(\diamond), \mathbf{2 d}(\diamond), \mathbf{3}(\nabla)$, and $\mathbf{4}($ (日) $)$.

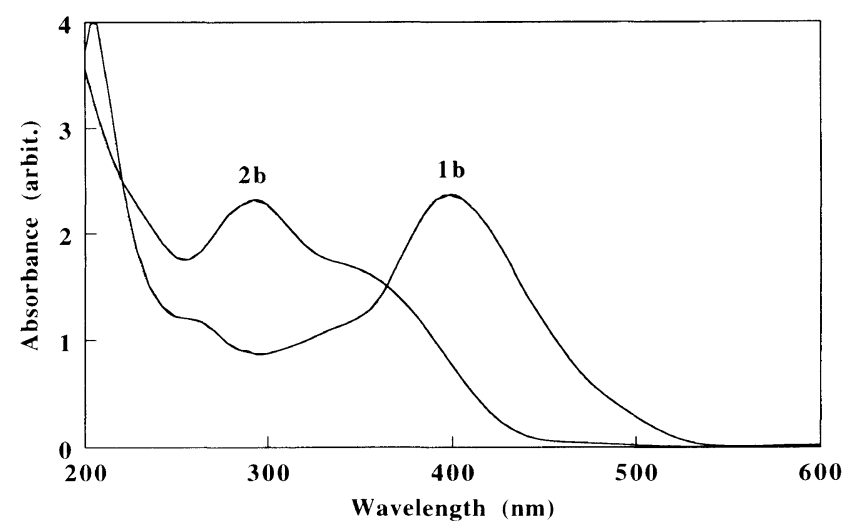

Figure 3. $U V /$ vis spectra of the thin film $\mathbf{1 b}$ and $\mathbf{2 b}$. 
shoulders for 2: as examples, UV/vis spectra of $\mathbf{1 b}$ and 2b are shown in Figure 3. The plots for 1c and the corresponding dimer and trimer (3 and 4) in Figure 2 follow a straight solid line represented by $\Delta=2 I^{\text {th }}+C$, where $C$ is a constant. ${ }^{18}$ It seems that the straight line relation of $\Delta$ and $I^{\text {th }}$ holds in spite of the difference in the degree of polymerization of the phenylenevinylene unit. Though the plots of $\mathbf{1 d}$ and $\mathbf{2} \mathbf{b}-\mathbf{d}$ almost coincide with the relationship, that of $\mathbf{1 b}$ deviates, which may be attributed to the strong electron donation by the hexyloxy group.

The authors previously reported that the value of $I^{\text {th }}$ for poly[(3,5-di-tert-butyl-4-oxyphenyl)acetylene] was significantly increased to $6.4 \mathrm{eV}$ from that of the corresponding precursor hydroxyl polymer $(5.5 \mathrm{eV})$; It was ascribed to the migration of an unpaired spin to the polyacetylene chain, which converted the phenoxy structure to a quinone methide structure and deconjugated the backbone. ${ }^{19}$ On the other hand, the values of $I^{\text {th }}$ of $1 \mathbf{e}, \mathbf{1 f}, \mathbf{2 e}$, and $\mathbf{2 f}$ in this paper are not enormously different from those of $\mathbf{1 c}, \mathbf{1 d}, \mathbf{2 c}$, and $\mathbf{2 d}$, respectively, in comparison with that of the polyacetylene-based polyradical. It indicates that the PPV structure is maintained even after the oxidation reaction. The small increase in $I^{\text {th }}$ for the polyradical derivatives 1 e, 1f, and $\mathbf{2 e}$, in comparison with those of $\mathbf{1 c}, \mathbf{2 d}$, and $\mathbf{2 c}$, respectively (Table I), is probably explained by the lowering of the energy level of the substituent group through the oxidation, and/or by the partial generation of the quinoid and quinone-imine $N$-oxide structure (evidenced by the appearance at $1600 \mathrm{~cm}^{-1}$ and $1625 \mathrm{~cm}^{-1}$ in IR absorption), respectively. The $I^{\text {th }}$ of $\mathbf{2} \mathbf{f}$ is smaller than that of $\mathbf{2 d}$, which is presumably due to increasing the chain-substituent mixing and/or intrachain conjugation. This is consistent with the result of ESR spectrum of $2 \mathbf{f}$ which shows hyperfine structure attributed to the PPV backbone proton, indicating the delocalization of spin density onto the PPV backbone.

Acknowledgment. This work was partially supported by Grants-in-Aid for Scientific Research on Priority Area "Molecular Magnetism" (Area No. 228/04242104) and for Scientific Research (Nos. 040852 and NP) from the Ministry of Education, Science, and Culture of Japan.

\section{REFERENCES AND NOTES}

1. H. H. Hörhold and M. Helbig, Makromol. Chem., Macromol. Symp., 12, 229 (1987).

2. G. A. Kossmehl, "Handbook of Conducting Polymers," Vol. 1, T. A. Skotheim, Ed., Marcel Dekker, Inc., New York, N.Y., and Basel, 1989, p 351 .

3. D. D. C. Bradley, Makromol. Chem., Macromol. Symp., 37, 247 (1990).

4. R. K. McCoy, F. E. Karasz, A. Sarker, and P. M. Lahti, Chem. Mater., 3, 941 (1991).

5. H. Nishide, T. Kaneko, Y. Kuzumaki, N. Yoshioka, and E. Tsuchida, Mol. Cryst. Liq. Cryst., 232, 143 (1993).

6. Z. Bao, Y. Chen, R. Cai, and L. Yu, Macromolecules, 26, 5281 (1993).

7. T. Kaneko, S. Toriu, Y. Kuzumaki, H. Nishide, and E. Tsuchida, Chem. Lett., 2135 (1994).

8. H. Nishide, T. Kaneko, T. Nii, K. Katoh, E. Tsuchida, and K. Yamaguchi, J. Am. Chem. Soc., 117, 548 (1995).

9. J. Obrzut and F. E. Karasz, J. Chem. Phys., 87, 2349 (1987).

10. K. Seki, S. Asada, T. Mori, H. Inokuchi, I. Murase, T. Ohnishi, and T. Noguchi, Solid State Commn., 74, 677 (1990).

11. N. Sato, M. Logdlund, R. Lazzaroni, W. R. Salaneck, J. L. Brédas, D. D. C. Bradley, R. H. Friend, and K. E. Ziemelis, Chem. Phys., 160, 299 (1992).

12. M. Dugay and C. Fabre, Solid State Commn., 47, 965 (1983).

13. P. M. Lahti, J. Obrzut, and F. E. Karasz, Macromolecules, 20, 2023 (1987).

14. O. Lhost and J. L. Brédas, J. Chem. Phys., 96, 5279 (1992).

15. S. Zalis and M. Kertesz, Synth. Met., 47, 179 (1992).

16. K. Seki, "Optical Techniques to Characterize Polymer Systems," H. Baessler, Ed., Elsevier Science Publishers, Amsterdam, 1989, p 115.

17. M. Fahlman, M. Lögdlund, S. Stafström, W. R. Salaneck, R. H. Friend, P. L. Burn, A. B. Holmes, K. Kaeriyama, Y. Sonoda, O. Lhost, F. Meyers, and J. L. Bréas, Macromolecules, 28, 1959 (1995).

18. The $\Delta$ and $I^{\text {th }}$ of an intrinsic semiconductor is approximately expressed as $\Delta=2\left(I^{\mathrm{th}}-E_{\mathrm{F}}\right)$, where $E_{\mathrm{F}}$ is the Fermi energy relative to the vacuum level. The line in Figure 2 is fitted through three points of 1c, $\mathbf{3}$, and $\mathbf{4}$ which have same substituent, because the substituent groups affect the electronic state of PPV. The constant $C$ is equal to $2 E_{\mathrm{F}}$ for an intrinsic semiconductor.

19. N. Yoshioka, H. Nishide, T. Kaku, T. Kaneko, E. Tsuchida, S. Narioka, and K. Seki, Polym. J., 23, 921 (1991). 